\title{
Drug-related problems in patients with erectile dysfunctions and multiple comorbidities
}

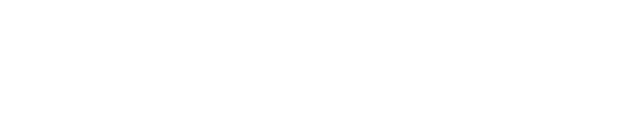

\author{
Hasniza Zaman Huri ${ }^{1,2}$ \\ Chui Fang Ling' \\ Azad Hassan Abdul Razack ${ }^{3}$ \\ 'Department of Pharmacy, Faculty \\ of Medicine, University of Malaya, \\ ${ }^{2}$ Clinical Investigation Centre, \\ University Malaya Medical Centre, \\ ${ }^{3}$ Department of Surgery, Faculty of \\ Medicine, University of Malaya, Kuala \\ Lumpur, Malaysia
}

\begin{abstract}
This study was conducted in a tertiary medical center in Kuala Lumpur, Malaysia. A total of 200 erectile dysfunction (ED) patients with 499 cases who had received pharmacological treatments for their ED participated in this study. Types, causes and factors associated with drug-related problems (DRPs) in ED patients with multiple comorbidities were assessed. A total of 244 DRPs with an average of 1.2 \pm 2.1 DRPs per patient were identified. Drug interaction contributed the most to DRPs occurrence. There was a significant higher risk of DRPs in patients with benign prostatic hyperplasia, lower urinary tract infection and elderly and endstage renal disease. Early identification of types of DRPs and factors associated may enhance their prevention and management.
\end{abstract}

Keywords: ED drugs, DRPs, factors associated, prevention and management

\section{Background}

Erectile dysfunction (ED), formerly known as impotence, is defined as "persistent inability to attain and maintain an erection sufficient to permit satisfactory sexual performance". ${ }^{1}$ It is a benign disorder that affects men, but the incidence increases with age as reported from 59 studies. $^{2}$ By 2025, 322 million men are predicted to have ED problems worldwide. ${ }^{3}$ The high prevalence of ED has drawn much concern due to its profound impact on physical and psychosocial health and quality of life of sufferers and their partners. ${ }^{4}$

Normal penile erection requires coordination between psychological, endocrine, vascular and neurological systems, and impairment or abnormalities of any of these can lead to ED. ED is classified into organic, psychogenic or mixed organic and psychogenic. ${ }^{5}$ Organic ED is caused by vascular, neurological and hormonal disorders, whereas psychogenic ED is due to any psychological factors that can affect normal erectile function. Approximately $80 \%$ of ED cases are of organic origin with vascular disease among the most common causes of ED. ${ }^{6}$

Treatments are available for certain types of ED, though only ED secondary to psychogenic causes, posttraumatic arteriogenic lesions and hormonal deficiency has shown evidence of being curable. ${ }^{7}$ The first-line therapy that is widely used is oral phosphodiesterase-5 (PDE5) inhibitors. Second-line treatment includes intracavernous or transurethral prostaglandin E1 injection and vacuum erection device, whereas penile prosthesis and revascularization surgery are third-line therapies. ${ }^{8}$ In addition to pharmacotherapy, lifestyle, risk factor modification, proper education and counseling to both patients and their partners play a crucial role in ED treatment. ${ }^{9}$

Certain drug-related problems (DRPs), defined as events or circumstances involving drug therapy, may actually or potentially interfere with desired health outcomes. ${ }^{10}$
Correspondence: Hasniza Zaman Huri Department of Pharmacy, Faculty of Medicine, University of Malaya, 50603 Kuala Lumpur, Malaysia

Tel +60 379676659

Fax +60 379674964

Email hasnizazh@um.edu.my 
Careful assessment of DRPs such as drug-drug interactions, dosing problems, drug choice or drug use problems and adverse reactions is essential to optimize treatment in ED patients with multiple comorbidities. This could also be significantly important in elderly with multiple comorbidities who are susceptible to polypharmacy. ${ }^{11,12}$

This study investigated the types, causes and factors associated with ED DRPs in ED patients with multiple comorbidities. The aim of our study was to provide baseline data regarding DRPs to allow implementation of more efficient management and to reduce the mortality and morbidity associated with DRPs.

\section{Methodology \\ Study design and setting}

This was an observational, retrospective study conducted in the University of Malaya Medical Centre (UMMC), a tertiary hospital in Malaysia with 1,200 beds.

\section{Study population and sampling frame}

Patients with ED who fulfilled the International Classification of Disease Tenth Revision (ICD 10) code F52.2 and Pharmacy Information System with a keyword sildenafil were included. The minimum sample size required was calculated using Epi Info Program version 7.0 (Centers for Disease Control and Prevention, Atlanta, GA, USA). The level of significance, $\alpha$, was set as 0.05 , and the desired power of the study $(1-\beta)$ was $80 \%$. The expected proportion of ED patients was based on the prevalence of $69.5 \%$ with a $5 \%$ confidence limit. ${ }^{13}$ The minimum sample size calculated was 148 patients.

\section{Study procedures}

The study was performed in accordance with the Declaration of Helsinki, and the medical ethics committee of the UMMC (reference number: 201410-705) approved the study. The committee waived the need for written informed consent from participants. Patient records and information were anonymized and de-identified prior to analysis. A total of 266 registration numbers of patients from January 2000 to December 2014 with an ICD code of F52.2 were selected, and 232 patients' medical folders were successfully retrieved from the Patient Medical Record office. Of these, 200 patients (499 cases) fulfilled the inclusion criteria (Figure 1). We counted each prescription/admission/clinic visit as a single case.

\section{Inclusion criteria}

- Diagnosed with any type of ED (organic, psychogenic or a combination of both) and had one or more comorbidities.

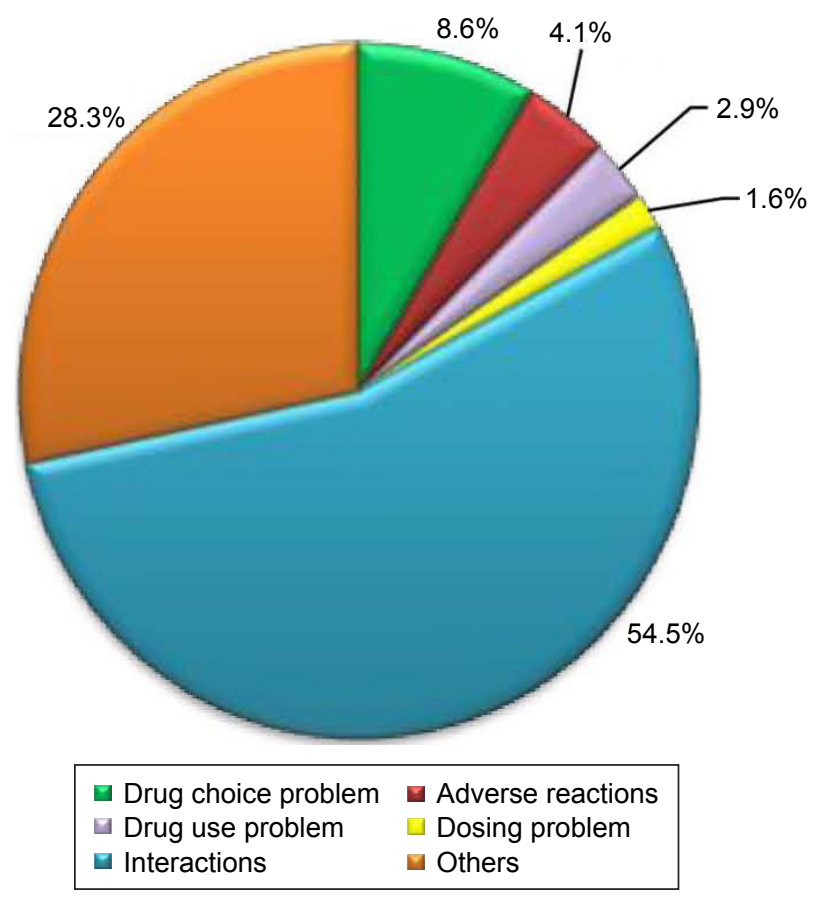

Figure I Drug-related problems ( $\mathrm{N}=244)$.

- Aged 18 years and above (pharmacological treatments for ED are indicated for patients with a minimum age of 18).

- Received pharmacological treatments, for instance, oral PDE-5 inhibitors (sildenafil, vardenafil, tadalafil), intracavernosal injection (aprostadil) or hormone replacement therapy (testosterone undecanoate and enanthate).

\section{Exclusion criteria}

- Received non-pharmacological treatments, for instance, psychosexual therapy and physiotherapy, vacuum erection device, penile prosthesis and penile revascularization therapy.

\section{Data collection}

Demographic data such as age, ethnicity, body mass index (BMI) and smoking and alcohol consumption status were collected. Clinical information such as the year of ED diagnosis, chronic comorbidities and concurrent medications, severity of ED, presence and type of hypogonadism and causes of DRPs was also collected. Table 1 defines terms used in this study.

\section{Classification and assessment of DRPs}

We used the Pharmaceutical Care Network Europe (PCNE) Classification for Drug Related Problems Version 5.01 (2006) as a tool to identify the types and causes of DRPs. 
Table I Definition of terms

\begin{tabular}{ll}
\hline Terms & Definitions \\
\hline Comorbidity & $\begin{array}{l}\text { Co-occurrence of any chronic diseases during } \\
\text { the clinical course of patient having ED }\end{array}$ \\
& 65 years old and above \\
Elderly & Underweight: $<18.5$; normal range: $18.5-22.9 ;$ \\
BMI range $\left(\mathrm{kg} / \mathrm{m}^{2}\right)$ & pre-obese: $23-27.4$; obese I: $27.5-34.9 ;$ \\
& obese II: $35.0-39.9^{16}$ \\
Polypharmacy & The use of five or more medications \\
Absolute & A contraindication for which a proposed \\
contraindication & treatment or intervention is impossible \\
Relative & A contraindication that applies in all but a few \\
contraindication & unusual or extreme mitigating circumstances \\
\hline
\end{tabular}

Abbreviations: ED, erectile dysfunction; BMI, body mass index.

There are six primary types of problems with 21 subtypes and six primary types of causes with 33 subtypes. The DRPs and their possible causes were identified from the patients' medical records, with reference to the standard guidelines from established literature. ${ }^{19-23}$ The references were used to assess the appropriateness of drug indications, appropriateness of drug and dosage, possible drug interactions and adverse drug reactions and contraindications. The authors who are pharmacists were involved in the identification and classification of DRPs.

\section{Statistical techniques}

Statistical Package for Social Science version 21 (SPSS) (SPSS Inc., Chicago, IL, USA) was used to analyze all the collected and extracted data. Normality test (ShapiroWilk's test) and visual inspection of the histogram, normal Q-Q plot and box plot were done to test the normality of continuous variables. The results were presented for skewness, kurtosis and standard error (SE). Normally distributed data were expressed as mean \pm standard deviation. Nominal and ordinal categorical data were expressed as frequency or percentage $(\%)$. Binary logistic regression was used to determine the associations between categorical variables, and results were presented as odds ratio, 95\% confidence interval level and $P$-value, where $<0.05$ indicated significance.

\section{Results}

A total of 499 cases and 200 male patients were included in this study. As shown in Table 2, the ethnicity of the majority was Chinese, followed by Malay and Indian. More than half of the patients were aged between 41 and 64 years and ranged from 31 to 91 years with a mean of $61.93 \pm 10.41$ years. A Shapiro-Wilk's test $(P>0.05)$ and a visual inspection of the histogram, normal Q-Q plot and box plot showed approximately normally distributed population ages among the

Table 2 Demographic characteristics of study population $(\mathrm{N}=200)$

\begin{tabular}{|c|c|c|c|}
\hline Characteristics & Number (\%) & With DRP (9I) (\%) & Without DRP ( 109$)(\%)$ \\
\hline \multicolumn{4}{|l|}{ Ethnicity } \\
\hline Chinese & $95(47.5)$ & $46(50.5)$ & $49(45.0)$ \\
\hline Malay & $70(35.0)$ & $27(29.7)$ & $43(39.4)$ \\
\hline Indian & $35(17.5)$ & I8 (19.8) & $17(15.6)$ \\
\hline \multicolumn{4}{|l|}{ Age groups } \\
\hline 18-40 years old & $7(3.5)$ & $3(3.3)$ & $4(3.7)$ \\
\hline $4 I-64$ years old & III (55.5) & $40(44.0)$ & $7 I(65 . I)$ \\
\hline$\geq 65$ years old & $82(4 I .0)$ & $48(52.7)$ & $34(3 \mid .2)$ \\
\hline \multicolumn{4}{|l|}{ BMI } \\
\hline Underweight $(<\mid$ I8.5) & $\mathrm{I}(0.5)$ & $\mathrm{I}(\mathrm{I} . \mathrm{I})$ & $0(0.0)$ \\
\hline Normal range (I8.5-22.9) & $21(10.5)$ & $8(8.8)$ & $13(11.9)$ \\
\hline Pre-obese $(23-27.4)$ & $54(27.0)$ & $32(35.2)$ & $22(20.2)$ \\
\hline Obese I (27.5-34.9) & $48(24.0)$ & $21(23.1)$ & $27(24.8)$ \\
\hline Obese II (35.0-39.9) & $3(1.5)$ & $0(0.0)$ & $3(2.8)$ \\
\hline Unknown & $73(36.5)$ & $29(31.9)$ & $44(40.4)$ \\
\hline \multicolumn{4}{|l|}{ Smoking } \\
\hline Nonsmoker & 79 (39.5) & $42(46.2)$ & 37 (33.9) \\
\hline Ex-smoker & $47(23.5)$ & $21(23.1)$ & $26(23.9)$ \\
\hline Smoker & $26(13.0)$ & $10(11.0)$ & $16(14.7)$ \\
\hline Unknown & $48(24.0)$ & $18(19.8)$ & $30(27.5)$ \\
\hline \multicolumn{4}{|l|}{ Alcohol } \\
\hline No & $68(34.0)$ & $30(33.0)$ & $38(34.9)$ \\
\hline Ex-drinker & $8(4.0)$ & $4(4.4)$ & $4(3.7)$ \\
\hline Yes & $43(21.5)$ & $20(22.0)$ & $23(2 I . I)$ \\
\hline Unknown & 81 (40.5) & 37 (40.7) & $44(40.4)$ \\
\hline
\end{tabular}

Note: $\mathrm{BMI}=$ weight $(\mathrm{kg}) /[$ height $\times$ height $(\mathrm{m})]$.

Abbreviations: DRP, drug-related problem; BMI, body mass index. 
Chinese (skewness of -0.264 with $\mathrm{SE}=0.247$, and kurtosis of -0.176 with $\mathrm{SE}=0.490$ ), Malay (skewness of -0.146 with $\mathrm{SE}=0.287$, and kurtosis of 0.283 with $\mathrm{SE}=0.566$ ) and Indian (skewness of -0.719 with $\mathrm{SE}=0.398$, and kurtosis of 0.503 with $\mathrm{SE}=0.778$ ). For BMI, only $63.5 \%$ of the data were retrievable, which showed that most of these patients were pre-obese followed by obese.

\section{Clinical characteristics}

The retrievable data showed that most of the patients had ED problem for 5-10 years. The mean of the ED onset age was 54 years with the earliest onset at 25 years and the latest at 76 years. Of 110 patients with an available record, $80 \%$ had ED onset between the ages of 40 and 64 years. On average, each patient had $3.5 \pm 1.5$ comorbidities with a range between 1 and 8 . Seventy-six percent of patients had three or more comorbidities. Hypertension, hyperlipidemia and type 2 diabetes mellitus (T2DM) were the top three leading comorbidities, and the other comorbidities were found in only $5.0 \%$ of patients or fewer. These included gout, nephropathy, glaucoma, atrial fibrillation, chronic kidney disease, fatty liver disease, depression, stroke, hypothyroidism, congestive heart failure, spinal cord injury, tuberculosis, ankylosing spondylitis, chronic pulmonary disease, thyrotoxicosis, end-stage renal failure and prostate cancer. In addition, other comorbidities only occurred in one patient. The number of medications taken ranged from 2 to 14 with an average of $5.9 \pm 2.5$ per patient. Polypharmacy was reported in $67.5 \%$ of the 200 participants and in $70.7 \%$ of the 82 elderly. Table 3 describes the clinical characteristics of the study population.

\section{Medications used in study population ED medications}

Sildenafil was the most common ED medication used, followed by vardenafil and tadalafil, both of which had a similar percentage of usage (Table 4). Sildenafil $50 \mathrm{mg}$, vardenafil $20 \mathrm{mg}$ and tadalafil $20 \mathrm{mg}$ were among the most commonly prescribed dosages compared to other dosing. The results also showed that alprostadil $(0.2 \%)$, testosterone undecanoate $(2.2 \%)$ and enanthate $(1.8 \%)$ were less common. The records retrieved from $61 \%$ of the 200 patients showed that for most had "Stable medication and dose", followed by "Change medication", "Change medication dose" and "Change medication and dose" (Figure 2). Seventy-five percent of 56 patients with stable medication and dosage were sildenafil users. Changing medication from sildenafil to tadalafil and vice versa had similar frequency (six out of

Table 3 Clinical characteristics of study population $(\mathrm{N}=200)$

\begin{tabular}{llll}
\hline Characteristics & Number (\%) & With DRP (9I) (\%) & Without DRP (I 09) (\%) \\
\hline $\begin{array}{l}\text { Duration of ED (years) } \\
<5\end{array}$ & $36(18.0)$ & $10(11.0)$ & $26(23.9)$ \\
$5-10$ & $63(31.5)$ & $30(33.0)$ & $33(30.3)$ \\
$>10$ & $11(5.5)$ & $8(8.8)$ & $3(2.8)$ \\
Unknown & $90(45.0)$ & $43(47.3)$ & $47(43.1)$ \\
Number of comorbidities & & & $10(9.2)$ \\
I & $14(7.0)$ & $4(4.4)$ & $25(22.9)$ \\
2 & $34(17.0)$ & $9(9.9)$ & $40(36.7)$ \\
3 & $66(33.0)$ & $26(28.6)$ & $22(20.2)$ \\
4 & $39(19.5)$ & $17(18.7)$ & $6(5.5)$ \\
5 & $25(12.5)$ & $19(20.9)$ & $4(3.7)$ \\
6 & $14(7.0)$ & $10(11.0)$ & $1(0.9)$ \\
7 & $5(2.5)$ & $4(4.4)$ & $1(0.9)$ \\
8 & $3(1.5)$ & $2(2.2)$ & $82(75.2)$ \\
Comorbidities & & & $79(72.5)$ \\
Hypertension & $152(76)$ & $70(76.9)$ & $66(60.6)$ \\
Hyperlipidemia & $147(73.5)$ & $68(74.7)$ & $10(9.2)$ \\
Type 2 diabetes mellitus & $113(56.5)$ & $47(51.6)$ & $21(19.3)$ \\
BPH & $54(27.0)$ & $44(48.4)$ & $8(7.3)$ \\
IHD & $45(22.5)$ & $24(26.4)$ & $7(6.4)$ \\
Osteoarthritis & $16(8.0)$ & $8(8.8)$ & $5(4.6)$ \\
Asthma & $14(7.0)$ & $7(7.7)$ & $6(5.5)$ \\
Allergic rhinitis & $13(6.5)$ & $7(7.7)$ & $27(29.7)$ \\
LUTS & $33(16.5)$ & &
\end{tabular}

Note: One patient may have one or more comorbidities.

Abbreviations: DRP, drug-related problem; ED, erectile dysfunction; BPH, benign prostatic hyperplasia; IHD, ischemic heart disease; LUTS, lower urinary tract symptoms. 
Table 4 Erectile dysfunction medications $(\mathrm{N}=499)$

\begin{tabular}{|c|c|}
\hline Type of medications $^{a}$ & Number of cases (\%) \\
\hline \multicolumn{2}{|l|}{ Sildenafil, total $=320(64.1 \%)(\mathrm{mg})$} \\
\hline 25 & $18(3.6)$ \\
\hline 50 & $170(34.1)$ \\
\hline 100 & $|3|(26.3)$ \\
\hline 200 & $\mathrm{I}(0.2)$ \\
\hline \multicolumn{2}{|l|}{ Vardenafil, total =93 (I8.6\%) (mg) } \\
\hline 5 & $2(0.4)$ \\
\hline 10 & $8(1.6)$ \\
\hline 20 & $80(16.0)$ \\
\hline 40 & $2(0.4)$ \\
\hline Unknown dose & $\mathrm{I}(0.2)$ \\
\hline \multicolumn{2}{|l|}{ Tadalafil, total =80 (I6.0\%) (mg) } \\
\hline 5 & $\mathrm{I}(0.2)$ \\
\hline 10 & $4(0.8)$ \\
\hline 20 & $75(15.0)$ \\
\hline Alprostadil injection & I $(0.2)$ \\
\hline Testosterone undecanoate I g & II (2.2) \\
\hline Testosterone enanthate & $9(1.8)$ \\
\hline
\end{tabular}

Note: a single case may have combination of medications or a patient may have changed his medication.

34 patients), and these changes occurred the most compared with the others.

\section{Concurrent medications}

Lipid-lowering agents, hypoglycemic agents, antiplatelet medications, antihypertensive agents and benign prostatic hyperplasia (BPH) medications were the concurrent medications highly utilized by ED patients. Some took one or more concurrent medications due to multiple comorbidities.

Statins as lipid-lowering agents were the most frequently prescribed concurrent medication in nearly three-quarters of the 499 cases. Simvastatin $20 \mathrm{mg}$ was the most commonly used statin in approximately $48 \%$ of 363 cases taking statins. Among hypoglycemic agents, biguanides were the most commonly used followed by sulfonylureas. Metformin 1,700/850 $\mathrm{mg}$ and gliclazide $120 \mathrm{mg} \mathrm{M} / \mathrm{R}$ were the highly

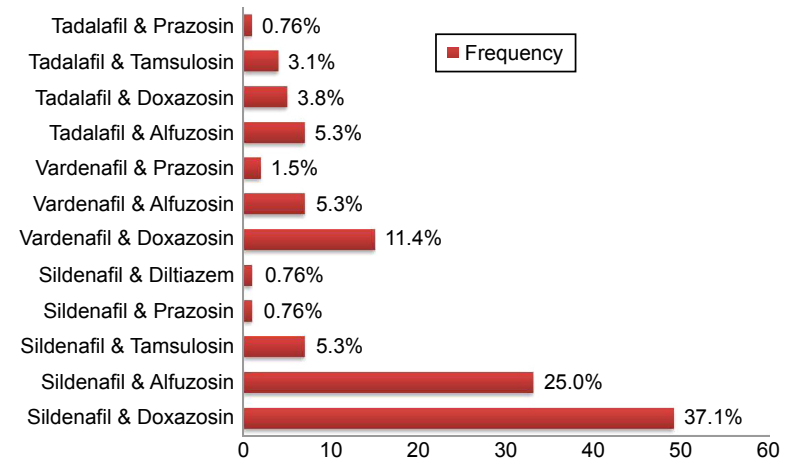

Figure 2 Potential interactions $(\mathrm{N}=132)$. utilized hypoglycemic agents representing biguanide and sulfonylurea, respectively.

Monotherapy aspirin $100 \mathrm{mg}$ was the most commonly used antiplatelet agent, which was prescribed in more than three-quarters of the 204 cases who took antiplatelets. Among antihypertensive agents, calcium channel blockers (CCBs) were most commonly used followed by angiotensinconverting enzyme (ACE) inhibitors, angiotensin II receptor blockers (ARBs) and thiazide diuretics. Amlodipine, perindopril, losartan and hydrochlorothiazide were the most widely used agents representing each class, respectively. Approximately $41 \%$ of 191 cases prescribed with CCBs used amlodipine $10 \mathrm{mg}, 33 \%$ of 164 cases prescribed with ACE inhibitors used perindopril $4 \mathrm{mg}, 31 \%$ of 143 cases prescribed with ARBs used losartan $100 \mathrm{mg}$ and more than half of 94 cases prescribed with thiazides used hydrochlorothiazide $25 \mathrm{mg}$.

Of the alpha-blockers, doxazosin $4 \mathrm{mg}$ was the most widely used in approximately half of the 147 cases who took alpha-blockers. This was followed by alfuzosin $10 \mathrm{mg} \mathrm{M} / \mathrm{R}$ (37.4\%) and tamsulosin $400 \mu \mathrm{g}(5.4 \%)$.

\section{Drug-related problems}

A total number of 244 DRPs were identified in 200 patients. On average, each patient had 1.2 \pm 2.1 DRPs with $1.2 \pm 2.1$ causes for the problems. The number of DRPs in each patient ranged from 0 to 11 , and $46.5 \%$ of the patients had at least one DRP. Under the six main types of problems, "Interactions" had the highest incidence followed by "Others", "Drug choice problems", "Adverse reactions", "Drug use problems" and "Dosing problems".

\section{Adverse reactions}

Ten cases of adverse reactions were identified and were mainly classified under the subtype "Side effect suffered (nonallergic)" (Table 5). All the nonallergic side effects reported were related to the use of PDE-5 inhibitors. Among the 320 sildenafil prescriptions, three cases (two cases of $100 \mathrm{mg}$ and one case of $50 \mathrm{mg}$ ) had reported side effects such as palpitation, flushing over face, blocked nose and headache. Of the 93 vardenafil prescriptions, side effects

Table 5 Adverse reactions $(\mathrm{N}=244)$

\begin{tabular}{lll}
\hline Code & Problems & $\begin{array}{l}\text { Number of } \\
\text { problems (\%) }\end{array}$ \\
\hline PI & Adverse reaction & $10(4.1)$ \\
PI.I & Side effect suffered (nonallergic) & $10(4.1)$ \\
\hline
\end{tabular}

Note: Only problems that have frequency $\geq$ I were included. 
Table 6 Drug choice problems $(\mathrm{N}=244)$

\begin{tabular}{lll}
\hline Code & Problems & $\begin{array}{l}\text { Number of } \\
\text { problems (\%) }\end{array}$ \\
\hline P2 & Drug choice problem & 2 I (8.6) \\
P2.3 & Inappropriate duplication of therapeutic & I (0.4) \\
& group or active ingredient & \\
P2.4 & Contraindication for drug & $20(8.2)$ \\
\hline
\end{tabular}

Note: Only problems that have frequency $\geq$ I were included.

were reported in six cases (four cases of $20 \mathrm{mg}$, one case of $10 \mathrm{mg}$ and one with unknown dosage), which included occasional and minimal flushing of face, headache, gastritis, weakness, palpitation, nausea and giddiness. One case of urine incontinence had been reported with the use of tadalafil $10 \mathrm{mg}$ from 80 prescriptions.

\section{Drug choice problems}

"Contraindication for drug" and "Inappropriate duplication of therapeutic group or active ingredient" were the two main drug choice problems (Table 6). The 20 cases identified as "Contraindication for drug" involved the concurrent use of PDE-5 inhibitors with isosorbide dinitrate (60\%) and glyceryl trinitrate (15\%), and the use of PDE-5 inhibitors in the presence of uncontrolled hypertension (20\%) and recent stroke $(5 \%)$. The percentage of cases in which nitrates were co-prescribed with sildenafil, vardenafil and tadalafil was $4.1 \%(n=320), 1.07 \%(n=93)$ and $1.25 \%(n=80)$, respectively. The single case of inappropriate duplication of therapeutic group involved the combined use of sildenafil $50 \mathrm{mg}$ and tadalafil $20 \mathrm{mg}$.

\section{Dosing problems}

Four dosing problems under the subtype "Drug dose too high or dosage regime too frequent" were identified (Table 7). Two of the four cases involved the use of a high initial dose of PDE-5 inhibitors. In one, sildenafil $50 \mathrm{mg}$ was used instead of $25 \mathrm{mg}$ as the initial dose for the patient on stable alpha-blocker, and the other had used sildenafil $100 \mathrm{mg}$ as the starting dose. In the other two cases, sildenafil $200 \mathrm{mg}$ and vardenafil $40 \mathrm{mg}$ exceeded the maximum daily dose that had been used.

Table 7 Dosing problems ( $\mathrm{N}=244)$

\begin{tabular}{lll}
\hline Code & Problems & $\begin{array}{l}\text { Number of } \\
\text { problems (\%) }\end{array}$ \\
\hline P3 & Dosing problem & $4(1.6)$ \\
P3.2 & Drug dose too high or dosage regime & $4(1.6)$ \\
& too frequent & \\
\hline
\end{tabular}

Note: Only problems that have frequency $\geq$ I were included.
Table 8 Drug use problems $(\mathrm{N}=244)$

\begin{tabular}{lll}
\hline Code & Problems & $\begin{array}{l}\text { Number of } \\
\text { problems (\%) }\end{array}$ \\
\hline P4 & Drug use problem & $7(2.9)$ \\
P4.I & Drug not taken/administered at all & $7(2.9)$ \\
\hline
\end{tabular}

Note: Only problems that have frequency $\geq$ I were included.

\section{Drug use problems}

Of 244 cases, only $2.9 \%$ had been detected as drug use problems. All the identified cases were under the subtype "Drug not taken/administered at all". Among the seven cases identified, six involved sildenafil, and one involved tadalafil (Table 8).

\section{Interactions}

"Interactions" was the most common DRP. The subtype "Potential interaction" comprised nearly $99 \%$ of the cases with only one case of "Manifested interaction" (Table 9). Potential interactions were detected between PDE-5 inhibitors with alpha-blockers (doxazosin, alfuzosin, tamsulosin, prazocin) and a CCB (diltiazem). As shown in Figure 2, the highest frequency of potential interaction was found between sildenafil and doxazosin (36.6\%). In addition, the "Manifested interaction" occurred between sildenafil and doxazosin.

\section{Others}

Approximately one-quarter (28.3\%) of cases were classified under "Others" with the main problem as "Dissatisfaction with therapy despite taking $\operatorname{drug}(\mathrm{s})$ correctly" (Table 10). Among the 69 cases, 33.4\% were identified as dissatisfaction with sildenafil $50 \mathrm{mg}, 23.3 \%$ with tadalafil $20 \mathrm{mg}, 21.7 \%$ with sildenafil $100 \mathrm{mg}$ and $8.7 \%$ with vardenafil $20 \mathrm{mg}$. Other minor complaints included therapy dissatisfaction towards testosterone enanthate, alprostadil, sildenafil $25 \mathrm{mg}$, tadalafil $5 \mathrm{mg}$, tadalafil $10 \mathrm{mg}$ and vardenafil $10 \mathrm{mg}$.

\section{Causes of DRPs}

We identified 244 causes of DRPs. "Drug use process" was the most common cause, which comprised more than half

Table 9 Drug interactions $(\mathrm{N}=244)$

\begin{tabular}{lll}
\hline Code & Problems & $\begin{array}{l}\text { Number of } \\
\text { problems (\%) }\end{array}$ \\
\hline P5 & Interactions & $133(54.5)$ \\
P5.I & Potential interaction & $132(54.1)$ \\
P5.2 & Manifested interaction & $\mathrm{I}(0.4)$ \\
\hline
\end{tabular}

Note: Only problems that have frequency $\geq$ I were included. 
Table 10 Other problems $(\mathrm{N}=244)$

\begin{tabular}{lll}
\hline Code & Problems & $\begin{array}{l}\text { Number of } \\
\text { problems (\%) }\end{array}$ \\
\hline P6 & Others & $69(28.3)$ \\
P6.1 & Dissatisfaction with therapy despite & $69(28.3)$ \\
& taking drug(s) correctly & \\
\hline
\end{tabular}

Note: Only problems that have frequency $\geq$ I were included.

of all causes. This was followed by "Others" (29.5\%), "Drug/ dose selection" (13.5\%) and "Patient/psychological" (1.6\%). The three most common subtypes of the causes included "Inappropriate timing of administration and/or dosing interval" of the type "Drug use process", "No obvious cause" of the type "Others" and "Inappropriate drug selection" of the type "Drug/dose selection" (Table 11).

\section{Factors associated with DRPs}

Patients with BPH, lower urinary tract symptoms (LUTS) and end-stage renal disease (ESRD) or elderly were significantly at higher risk of acquired DRPs (Table 12) and drug interactions (Table 13). In addition, LUTS, ESRD and elderly were also significantly associated with higher incidence of "Other" problems (Table 14). "Drug choice problems" was significantly more likely to occur in patients with ischemic heart disease (Table 15). However, T2DM patients were at lower risk of having DRPs $(P=0.011)$ and drug interactions $(P=0.024)$ compared with those without T2DM. Patients with hypertension were significantly at lower

Table I I Causes of drug-related problems $(\mathrm{N}=244)$

\begin{tabular}{lll}
\hline Code & Causes & $\begin{array}{l}\text { Number of } \\
\text { causes (\%) }\end{array}$ \\
\hline $\mathrm{Cl}$ & Drug/dose selection & $33(13.5)$ \\
$\mathrm{CI} .1$ & Inappropriate drug selection & $15(6.2)$ \\
$\mathrm{CI} .2$ & Inappropriate dosage selection & $4(1.6)$ \\
$\mathrm{Cl} .7$ & New symptom or indication revealed/ & $4(1.6)$ \\
& presented & \\
$\mathrm{Cl} .8$ & Manifested side effect, no other cause & $10(4.1)$ \\
$\mathrm{C} 2$ & Drug use process & $135(55.3)$ \\
$\mathrm{C} 2.1$ & Inappropriate timing of administration & $132(54.1)$ \\
& and/or dosing intervals & \\
$\mathrm{C} 2.2$ & Drug underused/under-administered & $\mathrm{I}(0.4)$ \\
$\mathrm{C} 2.3$ & Drug overused/over-administered & $2(0.8)$ \\
$\mathrm{C} 4$ & Patient/psychological & $4(1.6)$ \\
$\mathrm{C} 4.2$ & Patient has concerns with drugs & $\mathrm{I}(0.4)$ \\
$\mathrm{C} 4.3$ & Patient suspects side effect & $\mathrm{I}(0.4)$ \\
$\mathrm{C} 4.4$ & Patient unwilling to carry financial costs & $2(0.8)$ \\
$\mathrm{C} 6$ & Others & $72(29.5)$ \\
$\mathrm{C} 6.1$ & Other cause & $4(\mathrm{I} .6)$ \\
$\mathrm{C} 6.2$ & No obvious cause & $68(27.9)$ \\
\hline
\end{tabular}

Note: Only causes that have frequency $\geq$ I were included.
Table I 2 Factors associated with the occurrence of drug-related problems

\begin{tabular}{lll}
\hline Factors & Drug-related problems & \\
\cline { 2 - 3 } & Odd ratio $(95 \% \mathrm{CI})$ & P-value \\
\hline BPH & II.789 $(7.557-18.394)$ & $<0.00 I^{*}$ \\
LUTS & $6.718(4.052-1 \mathrm{I} .137)$ & $<0.00 I^{*}$ \\
Elderly & $2.418(1.655-3.532)$ & $<0.00 I^{*}$ \\
T2DM & $0.626(0.437-0.897)$ & $0.01 I^{*}$ \\
ESRD & $12.206(1.515-98.363)$ & $0.019^{*}$ \\
Hyperlipidemia & $0.912(0.616-1.350)$ & 0.644 \\
Hypertension & $0.920(0.597-1.420)$ & 0.708 \\
IHD & $1.028(0.679-1.557)$ & 0.896 \\
Polypharmacy & $1.007(0.689-1.472)$ & 0.969 \\
\hline
\end{tabular}

Note: *Statistically significant $(P<0.05)$.

Abbreviations: $\mathrm{Cl}$, confidence interval; BPH, benign prostatic hyperplasia; LUTS, lower urinary tract symptoms; T2DM, type 2 diabetes mellitus; ESRD, end-stage renal disease; IHD, ischemic heart disease.

risk of having "Drug use problems" (Table 16) and "Other" problems (Table 17). Polypharmacy was another factor significantly associated with lower risk of "Other" problems. For adverse reactions (Table 18) and dosing problems (Table 15), we found no significantly associated factor.

\section{Discussion}

Of the 110 patients with available records, the majority had onset of ED within the age range of 40-64 years. Although other studies have reported that ED affects nearly half of men aged over 40, its actual onset time is unknown. ${ }^{24}$ Therefore, we suggest future studies exploring both the timing of ED onset and whether it precedes or follows the associated comorbidities and the relationships between different comorbidities and ED onset must be conducted.

Hypertension, hyperlipidemia and T2DM were the three prevalent comorbidities found in the study population. Vascular abnormality is a common risk factor shared between these three comorbidities and ED. ${ }^{25}$ The strong association between ED and hypertension, hyperlipidemia and diabetes

Table 13 Factors associated with the occurrence of drug use problems

\begin{tabular}{lll}
\hline Factors & \multicolumn{2}{l}{ Drug use problems } \\
\cline { 2 - 3 } & Odd ratio $(95 \% \mathrm{CI})$ & P-value \\
\hline Polypharmacy & $0.08(0.01-0.673)$ & $0.020^{*}$ \\
Hypertension & $0.043(0.005-0.362)$ & $0.004^{*}$ \\
Hyperlipidemia & $0.301(0.067-1.363)$ & 0.119 \\
T2DM & $0.732(0.162-3.304)$ & 0.685 \\
BPH & $0.800(0.154-4.168)$ & $0.79 I$ \\
LUTS & $1.629(0.311-8.522)$ & 0.563 \\
\hline
\end{tabular}

Note: *Statistically significant $(P<0.05)$.

Abbreviations: $\mathrm{Cl}$, confidence interval; T2DM, type 2 diabetes mellitus; $\mathrm{BPH}$, benign prostatic hyperplasia; LUTS, lower urinary tract symptoms. 
Table I4 Factors associated with the occurrence of drug interactions

\begin{tabular}{|c|c|c|}
\hline \multirow[t]{2}{*}{ Factors } & \multicolumn{2}{|l|}{ Drug interactions } \\
\hline & Odd ratio $(95 \% \mathrm{Cl})$ & $P$-value \\
\hline BPH & 71.928 (36.798-140.596) & $<0.00 I^{*}$ \\
\hline LUTS & I2.075 (7.286-20.0II) & $<0.00 I^{*}$ \\
\hline Elderly & $3.964(2.614-6.013)$ & $<0.00 I^{*}$ \\
\hline T2DM & $0.448(0.298-0.675)$ & $<0.00 I^{*}$ \\
\hline ESRD & $23.360(2.893-188.629)$ & $0.003^{*}$ \\
\hline Hypertension & $1.247(0.757-2.056)$ & 0.386 \\
\hline Hyperlipidemia & $0.849(0.552-1.305)$ & 0.455 \\
\hline Polypharmacy & $0.882(0.58 I-\mid .338)$ & 0.554 \\
\hline IHD & I.085 (0.687-I.7|4) & 0.727 \\
\hline
\end{tabular}

Note: *Statistically significant $(P<0.05)$.

Abbreviations: $\mathrm{Cl}$, confidence interval; $\mathrm{BPH}$, benign prostatic hyperplasia; LUTS, lower urinary tract symptoms; T2DM, type 2 diabetes mellitus; ESRD, end-stage renal disease; IHD, ischemic heart disease.

found in other studies also supports this result. ${ }^{26-28}$ However, the prevalence rates of these three comorbidities were found to be higher than the study performed by Seftel et al on a large ED population (272,325 patients) in which hypertension was seen in $41.6 \%$, hyperlipidemia in $42.2 \%$ and diabetes mellitus in $20.2 \%{ }^{29}$ The small sample size used in our study is the most reasonable explanation for the higher percentage of disease occurrences.

We found that $16.5 \%$ of 200 ED patients had LUTS, which is similar to the finding of a recent study by Zaman Huri et al that showed $11 \%$ of 219 ED patients had LUTS. ${ }^{30}$ Other studies have found that LUTS is an independent risk factor for ED regardless of age and comorbidities. ${ }^{31}$

We observed polypharmacy in $67.5 \%$ of 200 patients, and $70.7 \%$ of the 82 elderly had polypharmacy. The presence of multiple diseases inevitably leads to the occurrence of polypharmacy, which is commonly observed in the elderly. ${ }^{32}$ A retrospective cohort study conducted in Italy, which

Table I 5 Factors associated with the occurrence of drug choice problems

\begin{tabular}{lll}
\hline Factors & \multicolumn{2}{l}{ Drug choice problems } \\
\cline { 2 - 3 } & Odd ratio $(95 \% \mathbf{C l})$ & P-value \\
\hline Elderly & $1.458(0.602-3.533)$ & 0.403 \\
Polypharmacy & $3.105(0.90 I-10.695)$ & 0.073 \\
Hypertension & $2.674(0.613-11.666)$ & 0.191 \\
Hyperlipidemia & $1.025(0.390-2.696)$ & 0.960 \\
IHD & $8.668(3.283-22.886)$ & $<0.00$ I* \\
T2DM & $0.590(0.240-1.450)$ & 0.250 \\
BPH & $1.533(0.633-3.716)$ & 0.344 \\
LUTS & $2.098(0.823-5.345)$ & 0.121 \\
\hline
\end{tabular}

Note: *Statistically significant $(P<0.05)$.

Abbreviations: $\mathrm{Cl}$, confidence interval; IHD, ischemic heart disease; T2DM, type 2 diabetes mellitus; BPH, benign prostatic hyperplasia; LUTS, lower urinary tract symptoms.
Table 16 Factors associated with the occurrence of dosing problems

\begin{tabular}{lll}
\hline Factors & \multicolumn{2}{l}{ Dosing problems } \\
\cline { 2 - 3 } & Odd ratio $(95 \% \mathrm{Cl})$ & P-value \\
\hline Polypharmacy & $\mathrm{I} .500(0.155-14.532)$ & 0.726 \\
BPH & $0.667(0.069-6.459)$ & 0.726 \\
Hyperlipidemia & $1.231(0.127-11.93 \mathrm{I})$ & 0.858 \\
Elderly & $0.956(0.086-10.617)$ & $0.97 \mathrm{I}$ \\
T2DM & $0.980(0.137-7.012)$ & 0.984 \\
\hline
\end{tabular}

Abbreviations: $\mathrm{Cl}$, confidence interval; $\mathrm{BPH}$, benign prostatic hyperplasia; T2DM, type 2 diabetes mellitus.

defined polypharmacy as five or more medications, found a prevalence of $39.4 \%$ polypharmacy among 887,165 elderly in outpatient settings. ${ }^{33}$ However, in our study, the prevalence of polypharmacy in elderly was misleadingly higher due to the small number of elderly.

\section{Drug-related problems}

This is the first study to investigate DRPs in ED patients with multiple comorbidities. We found that almost half of the patients had at least one DRP with "Interactions" and "Others" being the most commonly identified. A study of DRPs in T2DM patients with hypertension found $90.5 \%$ of 200 patients had at least one DRP with an average of $1.9 \pm 1.2$ problems per patient. ${ }^{34}$ Another study investigated DRPs in T2DM patients with hyperlipidemia and found $91.8 \%$ of 208 patients had at least one DRP with an average of $1.94 \pm 1.10$ problems per patient. ${ }^{35}$ Since DRPs in our study were only identified from the perspective of ED, higher incidences of DRPs are expected when DRP detection involves a wider perspective of different comorbidities. We suggest future studies are needed to detect DRPs from all the different disease perspectives to provide an overview of DRPs.

Table 17 Factors associated with the occurrence of other problems

\begin{tabular}{lll}
\hline Factors & \multicolumn{2}{l}{ Other problems } \\
\cline { 2 - 3 } & Odd ratio $(95 \%$ CI) & P-value \\
\hline LUTS & $2.329(I .332-4.07 I)$ & $0.003^{*}$ \\
ESRD & $5.23 \mathrm{I}(\mathrm{I} .369-19.985)$ & $0.016^{*}$ \\
Hypertension & $0.526(0.30 \mathrm{I}-0.92 \mathrm{I})$ & $0.024^{*}$ \\
Elderly & $\mathrm{I} .684(\mathrm{I} .006-2.820)$ & $0.048^{*}$ \\
BPH & $\mathrm{I} .55 \mathrm{I}(0.922-2.606)$ & 0.098 \\
IHD & $0.612(0.3 \mathrm{I}-\mathrm{I} .184)$ & 0.145 \\
Polypharmacy & $\mathrm{I} .487(0.838-2.637)$ & 0.175 \\
T2DM & $\mathrm{I} .324(0.794-2.210)$ & 0.282 \\
Hyperlipidemia & $0.792(0.460-\mathrm{I} .363)$ & 0.400 \\
\hline
\end{tabular}

Note: *Statistically significant $(P<0.05)$.

Abbreviations: $\mathrm{Cl}$, confidence interval; LUTS, lower urinary tract symptoms; ESRD, end-stage renal disease; BPH, benign prostatic hyperplasia; IHD, ischemic heart disease; T2DM, type 2 diabetes mellitus. 
Table 18 Factors associated with the occurrence of adverse reactions

\begin{tabular}{lll}
\hline Factors & \multicolumn{2}{l}{ Adverse reactions } \\
\cline { 2 - 3 } & Odd ratio $(95 \% \mathrm{CI})$ & P-value \\
\hline Elderly & $0.208(0.026-1.654)$ & 0.138 \\
Polypharmacy & $2.018(0.424-9.6 I 3)$ & 0.378 \\
BPH & $0.495(0.104-2.360)$ & 0.378 \\
Hypertension & $2.49 I(0.3 \mid 2-19.88 I)$ & 0.389 \\
LUTS & $0.443(0.056-3.54 I)$ & 0.443 \\
T2DM & $I .482(0.4 \mid 3-5.316)$ & 0.546 \\
IHD & $0.769(0.16 I-3.670)$ & 0.742 \\
\hline
\end{tabular}

Abbreviations: $\mathrm{Cl}$, confidence interval; BPH, benign prostatic hyperplasia; LUTS, lower urinary tract symptoms; T2DM, type 2 diabetes mellitus; IHD, ischemic heart disease.

\section{Adverse reactions}

The incidence of adverse reactions in our study only contributed to a small percentage of DRPs. All the cases of adverse reactions classified as subtype "Side effect suffered (nonallergic)" were related to the use of PDE-5 inhibitors. Despite the possibility of underreported adverse reactions in patients who were able to tolerate the side effects, this result indicated that only a minority of patients were not able to tolerate the side effects of PDE-5 inhibitors. However, a recent study found that the most common reason given by 70-79-year-old patients who discontinued the use of PDE-5 inhibitors was "Concern about the side effect of medications" because of their poor health condition and other comorbidities. ${ }^{36}$ Therefore, adverse reactions are still a major concern in elderly ED patients taking PDE-5 inhibitors.

\section{Drug choice problems}

We identified $20(8.2 \%)$ contraindications and one $(0.4 \%)$ case of inappropriate duplication of medication that were identified as drug choice problems. The percentage of nitrates co-prescribed with sildenafil, vardenafil and tadalafil was $4.1 \%(n=320), 1.07 \%(n=93)$ and $1.25 \%(n=80)$, respectively. This result was similar to the finding of Chang et al study that showed the co-prescribed percentages of $1.07 \%, 0.83 \%$ and $1.07 \%$ for sildenafil, vardenafil and tadalafil, respectively. ${ }^{37}$ Despite the overall result showing low incidence of contraindication, the need to double-check the intake of concomitant drugs is crucial for preventing severe hypotension..$^{38}$

There were four cases of concomitant use of PDE-5 inhibitors in patients with uncontrolled hypertension $(>170 / 110)$. Although low incidences were detected, caution still needs to be taken because the safety of PDE-5 inhibitors has not yet been established. ${ }^{39-41}$ Despite a recent study that explored the use of sildenafil in stroke recovery, the concomitant use of PDE-5 inhibitors in recent stroke is still not encouraged within 6 months following an acute stroke due to the lack of clinical data. ${ }^{42}$

In our study, an inappropriate duplication of medications involved a single case of co-prescribed sildenafil $50 \mathrm{mg}$ and tadalafil $20 \mathrm{mg}$. However, no study has been done on the safety and efficacy of this combination, though recently a study of the use of long-term tadalafil $5 \mathrm{mg}$ daily with sildenafil $50 \mathrm{mg}$ added for the first few weeks showed better ED improvement without any increased adverse events than using only tadalafil. ${ }^{43}$ However, further studies are required to provide more evidence-based data.

\section{Dosing problems}

We detected two cases of inappropriate initial dose of sildenafil. One case involved the use of sildenafil $50 \mathrm{mg}$ as the initial dose for a patient on stable alpha-blocker, and the other involved sildenafil $100 \mathrm{mg}$ as the starting dose for a patient with naive treatment. A low initial dose of PDE-5 inhibitors has been suggested for patients on stable alpha-blockers to minimize the risk of orthostatic hypotension. ${ }^{38,44}$ Despite recent studies that suggest the use of $100 \mathrm{mg}$ sildenafil as a starting dose due to several advantages such as reducing the need for titration and preventing discouragement and treatment abandonment, this starting dose in patients with naive treatment was still considered as a high initial dose in our study because of the recommended dose in the product insert. ${ }^{39,45,46}$ Although the result showed low incidence of inappropriate initial dosing, there might have been underestimation of incidence since not all cases were observed from the beginning.

In addition, the use of $200 \mathrm{mg}$ sildenafil and $40 \mathrm{mg}$ vardenafil that exceeded the maximum daily dose was identified. For sildenafil, a study by McMahon showed that $24.1 \%$ of patients who did not respond previously to a maximum dose of $100 \mathrm{mg}$ responded to a higher dose of $150 \mathrm{mg}$ and $200 \mathrm{mg}$; however, the usage was limited due to the high occurrence of side effects and a high rate of discontinuation. ${ }^{47}$ For vardenafil, studies have found no significant difference between the efficacies of $20 \mathrm{mg}$ and $40 \mathrm{mg}$, but there were slightly more side effects observed in those who took vardenafil $40 \mathrm{mg}$ compared with the placebo. ${ }^{48,49}$ Therefore, patients with a poor response were not encouraged to exceed the maximum dose, although they were currently using a maximum dose. Instead, other strategies such as patient education, improvement of comorbidities, normalization of testosterone level, switching PDE-5 inhibitors, daily or continuous use of PDE-5 inhibitors and psychosexual counseling could be tried for patients who are not keen on other ED treatments. ${ }^{50}$ 


\section{Drug use problems}

A minority of cases were identified as drug use problems when patients did not take the ED medications prescribed by the physician. Despite ED not being a life-threatening condition, studies have found that it can be a contributor to nonadherence to other long-term treatment for concurrent comorbidities if left untreated..$^{51}$ Psychological problems related to self-confidence, emotional states and the fear of medication adverse events were found to be the most common factor affecting the use of PDE-5 inhibitors. ${ }^{52}$ Other affecting factors included medication-related factors (cost, drug efficacy and side effects), relational factors (relationship with partner) and circumstance factors (nonscheduled medication intake and trying natural products). ${ }^{52}$ Therefore, the reason why a drug is not taken should be taken into consideration before further action.

\section{Interactions}

Potential interactions between PDE-5 inhibitors and alphablockers, primarily doxazosin, alfuzosin, tamsulosin and prazocin, were the most common DRPs in our study. One such interaction was between sildenafil and doxazosin, which could be explained by the significant association between BPH/LUTS and ED. ${ }^{30}$ Despite coadministration of alpha-blockers and PDE-5 inhibitors that possess the risk of hypotension, a recent systematic review had found that a combination of both agents in treating BPH/LUTS and ED was beneficial..$^{53}$ Nevertheless, PDE-5 inhibitors still need to be used with caution in combination with alphablockers. Apart from that, potential interactions between diltiazem and sildenafil had also been detected. Caution needs to be taken when diltiazem, sildenafil and nitrate are used concomitantly as a study has reported that diltiazemmediated inhibition of sildenafil metabolism may promote nitrate-induced hypotension. ${ }^{54}$

\section{Others}

The second most common DRP in our study was "Others" with all the cases identified under the subtype "Dissatisfaction with therapy despite taking drug(s) correctly". The most common complaint from patients was dissatisfaction with the use of sildenafil $50 \mathrm{mg}$, followed by tadalafil $20 \mathrm{mg}$, sildenafil $100 \mathrm{mg}$ and vardenafil $20 \mathrm{mg}$. The main reasons for the dissatisfaction were ineffectiveness of the medications. A recent study that assessed patients' satisfaction using a questionnaire had showed a high satisfaction rate $(95.5 \%)$ in users of PDE-5 inhibitors. ${ }^{55}$ In our study, the percentage of dissatisfaction might have been overestimated as therapeutic dissatisfaction of patients was judged on patients' feedback that was recorded on the medical notes without any rating. In addition, we had assumed that patients took the medication correctly.

\section{Causes of DRPs}

Among a total of 244 causes, "Drug use process" was the most common cause of DRPs followed by "Others", "Drug/ dose selection" and "Patient/psychological". Of the subtype "Drug use process", inappropriate timing of administration was the cause assigned for the potential interaction between PDE-5 inhibitors and alpha-blockers. Despite different doses, different timing and different types of combination with possible different degrees of interaction, the timing of administration between the PDE-5 inhibitors and alphablockers remained a concern. ${ }^{56}$ However, this result might be overestimated since patients might be warned of an appropriate timing of medication, which was not recorded in the medical note.

"No obvious cause" had been used to explain most of the cases of therapeutic dissatisfaction with unknown causes. This was necessary because of the limitation in obtaining the real causes of dissatisfaction, which was not recorded. "Other cause" explained other reasons for DRPs; for instance, spinal cord injury (SCI) might be the cause of therapeutic dissatisfaction. Patients with a low level of SCI lesion might have a poor response to PDE-5 inhibitors due to poor or impaired penile innervation. ${ }^{57}$ There were also some causes that were beyond the control of health care professionals. For instance, one patient with stroke within 6 months insisted on taking a PDE-5 inhibitor at his own risk, and another patient refused to take the prescribed ED drug to work on his confidence first.

For "Drug/dose selection", this involved inappropriate drug selection where PDE-5 inhibitors should not be given to patients who concurrently were prescribed another form of nitrate. A well-established screening process can minimize this problem. Apart from that, although "Patient/ psychological" only comprised minor causes, proper counseling can be given for patients who are concerned about the drugs or the side effects, whereas a financial problem might need to be personally solved by the patient.

\section{Factors associated with DRPs Benign prostatic hyperplasia/lower urinary tract symptoms}

We found that BPH and LUTS have a significant positive association with the occurrence of DRPs. This might be due 
to the relationship between ED, BPH and LUTS. ED and $\mathrm{BPH}$ are apparently linked together with a similar age and gender distribution, whereas BPH is the primary cause of LUTS. ${ }^{58,59}$ A recent study also proposed the co-diagnosis of LUTS and ED following preclinical evidence that had found several common pathophysiological mechanisms in them. ${ }^{30}$

Incidences of drug interactions were also significantly higher in patients with BPH and LUTS. The concurrent use of PDE-5 inhibitors for ED and alpha-blockers for BPH/LUTS had contributed to this. Despite recent studies and clinical trials that had found the efficacy of the combined use of alphablockers and PDE-5 inhibitors for both ED and BPH/LUTS, the potential interaction between them should also be considered. ${ }^{53,60}$ LUTS alone were also significantly associated with higher incidence of "Other" problems, which represent patients' dissatisfaction with therapy. The negative effect on quality of sexual life by LUTS might explain their contribution towards therapeutic dissatisfaction. ${ }^{31}$

\section{Elderly}

Elderly was significantly associated with higher occurrence of DRPs, drug interactions and "Others" problems. The presence of multiple comorbidities in ED patients might explain this association. ${ }^{11}$ Elderly patients were more susceptible and vulnerable to drug interaction and therapeutic dissatisfaction which might be due to age-related changes, for instance, changes in physiological, biological, physical and social functions. ${ }^{61}$

\section{End-stage renal disease}

We also found that ESRD was significantly associated with higher occurrence of DRPs. The complexity of medication management in ESRD patients can cause the occurrence of DRPs in them. ${ }^{62}$ In addition, the result of our study also showed that the occurrence of drug interaction was higher in ESRD patients compared with non-ESRD patients. Although the study by Rama et al had found a high occurrence of drug interaction in patients with ESRD, the interactions were not the result of ED medication. ${ }^{63}$ Therefore, further studies are required to validate this relationship. Furthermore, "Other" problems that represent patients' dissatisfaction with therapy were also significantly associated with ESRD. ESRD itself can cause ED because of the imbalance of hormone production through the hypothalamic-pituitary-gonadal axis and which accelerates the atherosclerosis process. ${ }^{64}$ The dissatisfaction of therapy might be due to the ESRD. However, one study has shown that most of the ESRD patients improved in penile erection with the use of PDE-5 inhibitors. ${ }^{65}$ Therefore, further studies are needed.

\section{Type 2 diabetes mellitus}

We found that T2DM has a negative association with DRPs and drug interactions. However, T2DM was commonly accompanied by other comorbidities that lead to management complexity. ${ }^{66}$ A recent study showed that at least one DRP had occurred in $91.8 \%$ of T2DM patients with hyperlipidemia, while another study found $90.5 \%$ of T2DM patients with hypertension had at least one DRP. ${ }^{34,35}$ The inconsistent result in our study might be due to DRPs being observed from different disease perspectives.

\section{Ischemic heart disease}

The contraindication of nitrate with PDE-5 inhibitors might be the link of significant association between ischemic heart disease and drug choice problems. Although PDE-5 inhibitors are contraindicated in patients who take any form of nitrates, for patients who develop ischemic heart disease after ED, nitrates are suggested not be taken within 24 hours of a sildenafil or vardenafil dose, and 48 hours of a tadalafil dose. In the case of emergency chest pain, non-nitrate-containing agents such as $\mathrm{CCB}$ or a beta blocker should substitute the use of nitrate. ${ }^{39-41,67,68}$

\section{Hypertension}

Patients with hypertension were significantly less likely to have therapeutic dissatisfaction. This indicates higher therapeutic satisfaction in hypertensive patients compared with patients without hypertension. Nonadherence and treatment discontinuation of antihypertensive agents were common DRPs found in hypertensive patients due to ED development after using certain antihypertensive medications (especially thiazide and beta-blockers). However, improvement in adherence to antihypertensive agents was observed when a PDE-5 inhibitor was given for ED. ${ }^{51,68,69}$ This suggests that proper management of both hypertension and ED might produce a better response towards therapy.

\section{Polypharmacy}

Drug use problems as indicated by "Drug not taken/ administered at all" were found to be significantly less likely to occur in patients with polypharmacy. Generally, polypharmacy was associated with higher risk of DRPs. ${ }^{32}$ Increased prescribed medications will generally lead to medication nonadherence. ${ }^{70}$ The only hypothesis that can be made from our study was that ED patients with polypharmacy might indicate the presence of multiple comorbidities. This 
might lead to more severe ED and the need to urge patients to adhere to ED medications. Further study is required to explore this relationship.

\section{Conclusion}

DRPs occurred in almost half of the total cases identified. "Drug interaction" and "Others" were the most common DRPs identified. Factors such as BPH, LUTS, ESRD and elderly were found to be significantly associated with the occurrence of DRPs. Therefore, early identification of the types and patterns of DRPs and the factors associated may enhance the prevention and management of DRPs in ED patients with multiple comorbidities.

\section{Limitation of the study}

The retrospective nature of the study can lead to risk of bias because it was highly dependent on patients' clinical records as the only data source which is a limitation to the study.

\section{Acknowledgments}

The authors would like to thank the University of Malaya, Malaysia (RP024A-14HTM) and the University Malaya High Impact Research Grant (HIR/MOHE/MED/35 to AHAR) for financial and technical support.

\section{Disclosure}

The authors declare that they have no competing interests in this work.

\section{References}

1. NIH Consensus Conference. Impotence. NIH Consensus Development Panel on Impotence. JAMA. 1993;270(1):83-90.

2. Lewis RW, Fugl-Meyer KS, Corona G, et al. Definitions/epidemiology/ risk factors for sexual dysfunction. J Sex Med. 2010;7(4 Pt 2): 1598-1607.

3. Ayta IA, McKinlay JB, Krane RJ. The likely worldwide increase in erectile dysfunction between 1995 and 2025 and some possible policy consequences. BJU Int. 1999;84(1):50-56.

4. Rosen RC, Fisher WA, Eardley I, Niederberger C, Nadel A, Sand M; Men's Attitudes to Life Events and Sexuality (MALES) Study. The multinational Men's Attitudes to Life Events and Sexuality (MALES) study: I. Prevalence of erectile dysfunction and related health concerns in the general population. Curr Med Res Opin. 2004;20(5):607-617.

5. Chao JK, Hwang TIS. Contemporary management of erectile dysfunction. Urol Sci. 2013;24(2):35-40.

6. Chiurlia E, D'Amico R, Ratti C, Granata AR, Romagnoli R, Modena MG. Subclinical coronary artery atherosclerosis in patients with erectile dysfunction. J Am Coll Cardiol. 2005;46(8):1503-1506.

7. Wespes E. Erectile dysfunction: the medical treatment. Eur Urol Suppl. 2013;12(2):13-17.

8. Hatzimouratidis K, Amar E, Eardley I, et al; European Association of Urology. Guidelines on male sexual dysfunction: erectile dysfunction and premature ejaculation. Eur Urol. 2010;57(5):804-814.

9. Wespes E, Eardley I, Giuliano F, et al. Guidelines on male sexual dysfunction: erectile dysfunction and premature ejaculation. European Association of Urology; 2014. Available from: https://uroweb.org/wp-content/ uploads/14-Male-Sexual-Dysfunction_LR.pdf. Accessed April 12, 2015.
10. Pharmaceutical Care Network Europe Foundation. PCNE Classification for Drug Related Problems. Version 5.01. 2010.

11. Gareri P, Castagna A, Francomano D, Cerminara G, De Fazio P. Erectile dysfunction in the elderly: an old widespread issue with novel treatment perspectives. Int J Endocrinol. 2014;2014:1-15.

12. Wooten J, Galavis J. Polypharmacy. Keeping the elderly safe. RN. 2005; 68(8):44-50.

13. Ab Rahman AA, Al-Sadat N, Yun Low W. Prevalence of erectile dysfunction in primary care setting, Malaysia. J Mens Health. 2011; 8 Suppl 1:S50-S53.

14. Valderas JM, Starfield B, Sibbald B, Salisbury C, Roland M. Defining comorbidity: implications for understanding health and health services. Ann Fam Med. 2009;7(4):354-363.

15. World Health Organization (WHO). Proposed working definition of an older person in Africa for the MDS Project. 2013. Available from: http://www.who.int/healthinfo/survey/ageingdefnolder/en/. Accessed May 20, 2015.

16. Zainudin S, Daud Z, Mohamad M, Tong Boon AT, Wan Mohamed WMI. A summary of the Malaysian clinical practice guidelines on management of obesity. J ASEAN Fed Endocr Soc. 2011;26(2).

17. Viktil KK, Blix HS, Moger TA, Reikvam A. Polypharmacy as commonly defined is an indicator of limited value in the assessment of drug-related problems. Br J Clin Pharmacol. 2007;63(2):187-195.

18. Venes D. Taber's Cyclopedic Medical Dictionary. Philadelphia USA: F.A. Davis Company; 2013.

19. Lacy CF, Armstrong LL, Goldman MP, Lance LL. Drug Information Handbook. 20th ed. Hudson, OH: Lexi-Comp Inc.; 2011.

20. MIMS Malaysia. 128th ed. UBM Medica Pacific Ltd; 2012.

21. Medscape. Alprostadil intracavernous/urethral (Rx). Available from: $\mathrm{http} / / /$ reference.medscape.com/drug/caverject-edex-alprostadil-342846. Accessed April 27, 2015.

22. Kloner RA. New drugs and technologies: cardiovascular effects of the 3 phosphodiesterase- 5 inhibitors approved for the treatment of erectile dysfunction. Circulation. 2004;110:3149-3155.

23. Straight Healthcare. Cytochrome P450 3A. Available from: http://www. straighthealthcare.com/cytochrome-p450-3a4.html\#how. Accessed April 27, 2015.

24. Nehra A, Kulaksizoglu H. Global perspectives and controversies in the epidemiology of male erectile dysfunction. Curr Opin Urol. 2002;12(6): 493-496.

25. Gandaglia G, Briganti A, Jackson G, et al. A systematic review of the association between erectile dysfunction and cardiovascular disease. Eur Urol. 2014;65(5):968-978.

26. Virag R, Bouilly P, Frydman D. Is impotence an arterial disorder? A study of arterial risk factors in 440 impotent men. Lancet. 1985; 1(8422):181-184.

27. Javaroni V, Neves MF. Erectile dysfunction and hypertension: impact on cardiovascular risk and treatment. Int J Hypertens. 2012;2012:627278.

28. Nunes KP, Labazi H, Webb RC. New insights into hypertensionassociated erectile dysfunction. Curr Opin Nephrol Hypertens. 2012; 21(2):163-170.

29. Seftel AD, Sun P, Swindle R. The prevalence of hypertension, hyperlipidemia, diabetes mellitus and depression in men with erectile dysfunction. J Urol. 2004;171(6 Pt 1):2341-2345.

30. Zaman Huri H, Lian Choo T, Sulaiman CZ, Mark R, Abdul Razack AH. Oral drug treatments in patients with erectile dysfunction and multiple comorbidities: a retrospective observational study. BMJ Open. 2014; 4(7):e005381.

31. Kirby M, Creanga DL, Stecher VJ. Erectile function, erection hardness and tolerability in men treated with sildenafil $100 \mathrm{mg}$ vs. $50 \mathrm{mg}$ for erectile dysfunction. Int J Clin Pract. 2013;67(10):1034-1039.

32. Nobili A, Garattini S, Mannucci PM. Multiple diseases and polypharmacy in the elderly: challenges for the internist of the third millennium. JOC. 2011;1(1):28-44.

33. Slabaugh SL, Maio V, Templin M, Abouzaid S. Prevalence and risk of polypharmacy among the elderly in an outpatient setting: a retrospective cohort study in the Emilia-Romagna region, Italy. Drugs Aging. 2010; 27(12):1019-1028 
34. Zaman Huri H, Fun Wee H. Drug related problems in type 2 diabetes patients with hypertension: a cross-sectional retrospective study. $B M C$ Endocr Disord. 2013;13:2.

35. Zaman Huri H, Chai Ling L. Drug-related problems in type 2 diabetes mellitus patients with dyslipidemia. BMC Pub Health. 2013;13:1192.

36. Kim S-C, Lee Y-S, Seo K-K, Jung G-W, Kim T-H. Reasons and predictive factors for discontinuation of PDE-5 inhibitors despite successful intercourse in erectile dysfunction patients. Int J Impot Res. 2014; 26(3):87-93.

37. Chang LL, Ma M, Allmen HV, Henderson SC, Harper K, Hornbuckle K. Co-possession of phosphodiesterase type-5 inhibitors (PDE5-I) with nitrates. Curr Med Res Opin. 2010;26(6):1451-1459.

38. Schwartz BG, Kloner RA. Drug interactions with phosphodiesterase-5 inhibitors used for the treatment of erectile dysfunction or pulmonary hypertension. Circulation. 2010;122(1):88-95.

39. Viagra $^{\circledR}$ (sildenafil) [prescribing information]. Pfizer; 2010.

40. Levitra ${ }^{\circledR}$ (vardenafil) [prescribing information]. Wayne, NJ: Bayer Healthcare/GlaxoSmithKline; 2011.

41. Cialis ${ }^{\circledR}$ (tadalafil) [prescribing information]. Indianapolis, IN: Eli Lilly; 2011.

42. Sandner P, Hutter J, Tinel H, Ziegelbauer K, Bischoff E. PDE5 inhibitors beyond erectile dysfunction. Int J Impot Res. 2007;19(6):533-543.

43. Cui H, Liu B, Song Z, et al. Efficacy and safety of long-term tadalafil $5 \mathrm{mg}$ once daily combined with sildenafil $50 \mathrm{mg}$ as needed at the early stage of treatment for patients with erectile dysfunction. Andrologia. 2015;47(1):20-24.

44. Kloner RA, Sadovsky R, Johnson EG, Mo D, Ahuja S. Efficacy of tadalafil in the treatment of erectile dysfunction in hypertensive men on concomitant thiazide diuretic therapy. Int J Impot Res. 2005;17(5): 450-454.

45. Ströberg P, Kaminetsky JC, Park NC, Goldfischer ER, Creanga DL, Stecher VJ. Hardness, function, emotional well-being, satisfaction and the overall sexual experience in men using 100-mg fixed-dose or flexible-dose sildenafil citrate. Int J Impot Res. 2010;22(4):284-289.

46. Kirby M, Chapple C, Jackson G, et al. Erectile dysfunction and lower urinary tract symptoms: a consensus on the importance of co-diagnosis. Int J Clin Pract. 2013;67(7):606-618.

47. McMahon CG. High dose sildenafil citrate as a salvage therapy for severe erectile dysfunction. Int J Impot Res. 2002;14(6):533-538.

48. Stark S, Sachse R, Liedl T, et al. Vardenafil increases penile rigidity and tumescence in men with erectile dysfunction after a single oral dose. Eur Urol. 2001;40(2):181-188; discussion 181-190.

49. Crowe SM, Streetman DS. Vardenafil treatment for erectile dysfunction. Ann Pharmacother. 2004;38(1):77-85.

50. Park NC, Kim TN, Park HJ. Treatment strategy for non-responders to PDE5 inhibitors. World J Mens Health. 2013;31(1):31-35.

51. Scranton RE, Goldstein I, Stecher VJ. Erectile dysfunction diagnosis and treatment as a means to improve medication adherence and optimize comorbidity management. J Sex Med. 2013;10(2):551-561.

52. Carvalheira A, Forjaz V, Pereira NM. Adherence to phosphodiesterase type 5 inhibitors in the treatment of erectile dysfunction in long-term users: how do men use the inhibitors? Sex Med. 2014;2(2):96-102.

53. Yan H, Zong H, Cui Y, Li N, Zhang Y. The efficacy of PDE5 inhibitors alone or in combination with alpha-blockers for the treatment of erectile dysfunction and lower urinary tract symptoms due to benign prostatic hyperplasia: a systematic review and meta-analysis. $J$ Sex Med. 2014;11(6):1539-1545.

Therapeutics and Clinical Risk Management

\section{Publish your work in this journal}

Therapeutics and Clinical Risk Management is an international, peerreviewed journal of clinical therapeutics and risk management, focusing on concise rapid reporting of clinical studies in all therapeutic areas, outcomes, safety, and programs for the effective, safe, and sustained use of medicines. This journal is indexed on PubMed Central, CAS,
54. Howes L. Diltiazem-mediated inhibition of sildenafil metabolism may promote nitrate-induced hypotension. Int Med J. 2001;31(6):373; author reply $374-375$.

55. Huang ST, Jiann BP. Assessing satisfaction in men and their female partners after treatment with phosphodiesterase type 5 inhibitors for erectile dysfunction. Int J Impot Res. 2013;25(5):178-182.

56. Kloner R. Erectile dysfunction and hypertension. Int J Impot Res. 2007; 19(3):296-302.

57. Brackett NL, Lynne CM, Ibrahim E, Ohl DA, Sonksen J. Treatment of infertility in men with spinal cord injury. Nat Rev Urol. 2010;7(3): $162-172$.

58. Vale J. Benign prostatic hyperplasia and erectile dysfunction - is there a link? Curr Med Res Opin. 2000;16 Suppl 1:s63-s67.

59. Rosen RC, Giuliano F, Carson CC. Sexual dysfunction and lower urinary tract symptoms (LUTS) associated with benign prostatic hyperplasia (BPH). Eur Urol. 2005;47(6):824-837.

60. Govorov A, Kasyan G, Priymak D, Pushkar D, Sorsaburu S. Tadalafil in the management of lower urinary tract symptoms: a review of the literature and current practices in Russia. Cent Eur J Urol. 2014;67(2): $167-177$.

61. Stegemann S, Ecker F, Maio M, et al. Geriatric drug therapy: neglecting the inevitable majority. Ageing Res Rev. 2010;9(4):384-398.

62. Stemer G, Lemmens-Gruber R. Clinical pharmacy activities in chronic kidney disease and end-stage renal disease patients: a systematic literature review. BMC Nephrol. 2011;12:35.

63. Rama M, Viswanathan G, Acharya LD, Attur RP, Reddy PN, Raghavan SV. Assessment of drug-drug interactions among renal failure patients of nephrology ward in a south Indian tertiary care hospital. Indian J Pharm Sci. 2012;74(1):63-68.

64. Ayub W, Fletcher S. End-stage renal disease and erectile dysfunction Is there any hope? Nephrol Dial Transplant. 2000;15(10):1525-1528.

65. Lasaponara F, Sedigh O, Pasquale G, et al. Phosphodiesterase type 5 inhibitor treatment for erectile dysfunction in patients with end-stage renal disease receiving dialysis or after renal transplantation. J Sex Med. 2013; 10(11):2798-2814.

66. Piette JD, Kerr EA. The impact of comorbid chronic conditions on diabetes care. Diabetes Care. 2006;29(3):725-731.

67. Rosen RC, Jackson G, Kostis JB. Erectile dysfunction and cardiac disease: recommendations of the Second Princeton Conference. Curr Urol Rep. 2006;7(6):490-496.

68. McLaughlin T, Harnett J, Burhani S, Scott B. Evaluation of erectile dysfunction therapy in patients previously nonadherent to long-term medications: a retrospective analysis of prescription claims. Am J Ther. 2005;12(6):605-611.

69. Viigimaa M, Vlachopoulos C, Lazaridis A, Doumas M. Management of erectile dysfunction in hypertension: tips and tricks. World J Cardiol. 2014;6(9):908-915.

70. Golchin N, Frank SH, Vince A, Isham L, Meropol SB. Polypharmacy in the elderly. J Res Pharm Pract. 2015;4(2):85-88.

\section{Dovepress}

EMBase, Scopus and the Elsevier Bibliographic databases. The manuscript management system is completely online and includes a very quick and fair peer-review system, which is all easy to use. Visit http://www.dovepress.com/testimonials.php to read real quotes from published authors. 